\title{
Celso Furtado, a ascensão chinesa e a complexificação do sistema centro-periferia
}

\section{Celso Furtado, the rise of China and the rearrangement of the center-periphery system}

\author{
Alexandre de Freitas Barbosa ${ }^{\star}$
}

Resumo: $O$ presente artigo apresenta as reflexões de Celso Furtado sobre o desenvolvimento da China. Na primeira parte, procura-se mostrar como a ampliação do seu arsenal metodológico, nas obras do final dos anos 1970, permite incorporar a China e os dilemas vividos pelo país durante o período das reformas à sua agenda de pesquisa. Na segunda parte, o artigo se detém na compreensão de Furtado sobre as transformações econômicas e geopolíticas do "capitalismo global" anos 1990 e o crescente papel exercido pela China. Na última parte do artigo, o autor procura traçar seu próprio itinerário de reflexões sobre a ascensão chinesa, revelando como essa nova perspectiva furtadiana pode se revelar fértil, especialmente se posta em diálogo com os conceitos e interpretações de outros autores como Fernand Braudel, Immanuel Wallerstein e Giovanni Arrighi.

Palavras-chave: Ascensão chinesa. Desenvolvimento. Dependência. Civilização industrial. Sistema centro-periferia.

Abstract: This article presents Celso Furtado's thinking about development in China. In the first part, it is shown how the broadening of his methodological approach paves the way for incorporating, at the end of the 1970's, China's main dilemmas during the period of economic reforms into his research agenda. Secondly, the article seeks to understand Furtado's view on the economic and geopolitical transformations faced by global capitalism in the 1990's and the increasing role played by China. At last, the author traces his own itinerary in search of understanding the rise of China. The idea is to point out how this new perspective launched by Furtado can be fruitful especially in dialogue with the concepts and views of Fernand Braudel, Immanuel Wallerstein and Giovanni Arrighi.

Keywords: Rising China. Development. Dependency. Industrial civilization. Center-periphery system.

\footnotetext{
* Submissão: 23/12/2020 | Aprovação: 15/01/2021 | DOI: 10.29182/hehe.v24i1.791

$\star \star$ Professor de História Econômica e Economia Brasileira do Instituto de Estudos Brasileiros da Universidade de São Paulo (IEB/USP) e bolsista Produtividade CNPq (categoria 2) | E-mail afbarbosa@usp.br | ORCID: 0000-0002-0493-7488
} 


\section{Introdução}

O título do artigo pode causar estranheza,já que Furtado não utilizou o seu arsenal metodológico para compreender o significado da ascensão chinesa para a transformação do "capitalismo global” no pós-1980. As várias menções à China na sua vasta obra são geralmente episódicas. Entretanto, impressiona a sua capacidade de fisgar aspectos essenciais dessa civilização em transformação, articulando as dimensões econômica, política, social e cultural. Já nos anos 1990, o economista percebe a ascensão chinesa como uma das linhas mestras a estruturar o novo sistema mundial em termos econômicos e geopolíticos. Apesar de as referências à China, neste último período, aparecerem em livros sucintos, mais lançando hipóteses do que realizado sínteses totalizantes, elas se revelam importantes, pois trazem reflexões que podem ser aprofundadas, justamente por destoarem de muitas interpretações correntes sobre a ascensão chinesa.

Este artigo percorre dois caminhos. $\mathrm{O}$ primeiro situa as principais menções à China na obra do Furtado, tecidas com auxílio do arcabouço analítico mais amplo elaborado pelo autor acerca da "civilização industrial" a partir do final dos anos 1970. Alguns depoimentos de Furtado sobre as suas viagens à China, quando ele nos apresenta as suas "impressões" gerais, são elucidativos. Lembremos que toda visita do economista a um espaço-tempo específico é um convite para mobilizar o seu repertório metodológico. Ele precisava "ver" para tirar conclusões.

O segundo percurso acompanha as suas reflexões sobre a China no momento em que a nação continental aparece como um dos protagonistas do processo de transformação do sistema mundial nos anos 1990. Não se imaginava então os movimentos tectônicos que levariam a uma des(re)organização da economia-mundo capitalista, acompanhada de uma complexificação do sistema centro-periferia.

Ao final, segue um depoimento do autor deste artigo contando a sua própria tentativa de compreender a ascensão chinesa, e de como essa releitura a partir da obra de Furtado contribuiu para ampliar os horizontes de suas pesquisas sobre o tema.

\section{A China na obra de Furtado}

Após o fecundo período cepalino, Celso Furtado desenvolve à sua maneira o método histórico-estrutural, de modo a compreender a dinâmica das 
estruturas de forma casada à dos centros de decisão numa perspectiva histórica da longa duração. O economista, em Formação econômica do Brasil, aplica com originalidade uma metodologia de análise que transcende a economia, fazendo-a imbricar-se com a história e com as possibilidades (em grande medida abortadas) de transformação das estruturas econômicas, recorrendo para tanto às estruturas sociais e de poder e aos hábitos de pensamento correlatos. Brasil, Inglaterra e Estados Unidos surgem como "tipos ideais" ao refletirem suas particularidades históricas. Em 1969, Furtado amplia o afresco para a América Latina, fazendo uso de sua tipologia das estruturas para entender as especificidades dos países da região. ${ }^{1}$

Entretanto, se o sistema centro-periferia abarca potencialmente a totalidade mundial, o cerne da sua análise concentra-se no período do imediato pós-Segunda Guerra e nas relações entre o novo centro dinâmico (Estados Unidos) e a sua periferia mais próxima (América Latina).Vale mencionar que as noções de um "sistema-mundo", ou de várias "economias-mundo" em competição, são formuladas, respectivamente, por Immanuel Wallerstein e Fernand Braudel ao longo dos anos 1970, tendo geralmente como foco o período anterior à Revolução Industrial. ${ }^{2}$

A recente publicação de diários e manuscritos de Celso Furtado permite mostrar que a China sempre esteve no seu radar, mesmo quando não incorporada ao seu esquema metodológico, o que acontece ao final dos anos 1970.

Vejamos um exemplo do início da sua trajetória. O jovem positivista, em trabalho para uma disciplina no Ginásio Pernambucano, já em 1938, tenta inserir "a economia dentro no quadro geral da vida". Imaginar que um só regime econômico irá "predominar" é pura "ideologia". Depois de mencionar que "o que é verdade no Japão não é obrigatoriamente na Rússia", ele afirma:"o complexo de vida de cada nação possui características próprias". As "condições de vida exigidas" por um estudante brasileiro, por exemplo, "não se confundem com as de um estudante chinês" (D’Aguiar, 2014, p. 41, $43-45,47) .^{3}$

\footnotetext{
${ }^{1}$ É quando se publica Formação econômica da América Latina, mais adiante intitulado A economia latino-americana (formação histórica e problemas contemporâneos). Em prefácio à segunda edição, Furtado menciona que a América Latina "contempla uma diversidade de situações que cobre toda a gama contemporânea do subdesenvolvimento" (Furtado, [1969] 1986, p. ix).

${ }^{2}$ Furtado ([1976] 1977, p. 37 e 40) faz menção às duas obras, The modern word-system (vol. I, 1974) de Wallerstein, que lhe permite comparar a experiência europeia com a chinesa; e Civilisation matérielle et capitalisme (vol. I, 1967) de Braudel. O historiador francês desenvolve o conceito de economia-mundo em toda a sua amplitude apenas no volume III da sua trilogia, publicado em 1979.

${ }^{3}$ O manuscrito "Liberalismo econômico" foi apresentado em sala de aula no dia 17 de outubro de 1938.
} 
A menção à China nesse trecho não é necessariamente fortuita. $\mathrm{O}$ jovem Furtado terminara de ler alguns meses antes o livro China, velha China, de Pearl Buck (Furtado, 2019), ${ }^{4}$ sinóloga e escritora estadunidense, que funcionou como uma espécie de porta de acesso do mundo ocidental à vida rural daquele país antes da Revolução Comunista.

É de se imaginar que o conhecimento de Furtado sobre a China tenha se ampliado ao longo do tempo, especialmente durante o exílio na França, quando a Revolução Cultural Chinesa (1966-1976) foi acompanhada de perto pela intelectualidade francesa. A partir dos acervos do intelectual, poderão ser mapeados os livros que ele leu sobre a China e algumas de suas reflexões sobre as transformações vivenciadas pela nação asiática no período posterior a 1949.

Mas é digno de nota que o esquema metodológico de Furtado se amplia entre 1976 e 1980, período em que ele navega na "grande teoria" (Mallorquin, 2005, p. 259-262), depois de perceber que o estruturalismo latino-americano apresentava "rendimentos decrescentes" (Furtado, 1977, p. 14). ${ }^{5}$

Esse esforço se completa com a sua "antropologia filosófica" voltada à investigação das formações sociais por meio de uma "visão global do capitalismo". No seu entender, a reflexão sobre o (sub)desenvolvimento exige "uma aproximação da teoria da acumulação com a teoria da estratificação social e a teoria do poder". Neste sentido, deve-se compreender a diversidade do processo de acumulação no tempo e no espaço, captando as projeções dessa diversidade nos países periféricos, por meio das "vinculações entre as relações externas e as formas internas de dominação social" (Furtado, [1980] 2000, p. 7, 29-30). ${ }^{6}$

No seu "antilivro-acadêmico" de 1978, Criatividade e dependência na civilização industrial, a China é incorporada ao seu esquema metodológico ampliado como hipótese a ser "checada". Como quem sobrevoa história em busca de novas ferramentas analíticas, Furtado mapeia a consolidação da civilização industrial na Europa Ocidental.

\footnotetext{
${ }^{4}$ O livro foi lido em 1938 em Recife, conforme anotação no seu diário de 22/06/1938. O título da obra de Peal Buck mencionada refere-se à primeira edição realizada pela Editora Globo, de 1937. As edições seguintes em português já trazem o título mais conhecido de $A$ boa terra.

${ }^{5}$ A primeira edição de Prefácio à nova economia política é de 1976.

${ }^{6}$ Trata-se da terceira edição revisada pelo autor de livro publicado em 1980 sob nome ligeiramente diferente: Pequena introdução do desenvolvimento: um enfoque interdisciplinar.
} 
A abertura de linhas comercias de amplitude planetária na primeira metade do século XVI permite a certas regiões da Europa ampliar a "extração de excedente mercantil" por meio de operações comerciais, de forma articulada à "extração de excedente por via autoritária" das regiões conquistadas. A subordinação das atividades diretamente produtivas ao mercado e à lógica da acumulação, no sentido de desenvolvimento das forças produtivas, não pode ser compreendida sem a conformação de uma nova estrutura de poder sob domínio da burguesia, na medida em que "a pressão sobre o quadro institucional tende a perpetuar-se". Portanto, o novo sistema de dominação social - a revolução burguesa - não se explica fora do contexto de expansão da civilização industrial na sua manifestação europeia (Furtado, 1978, p. 34-40).

Por outro lado, a "difusão da civilização industrial pertence a outro processo histórico", o qual não se pode compreender conceitualmente como "mera derivação da experiência histórica europeia" (Furtado, 1978, p. 37). O autor está ampliando o horizonte analítico de Desenvolvimento e subdesenvolvimento, ${ }^{7}$ obra de 1961, em que os sistemas sociais globais engendrados no espaço-tempo europeu aparecem descritos como "economia comercial" e "economia industrial", sujeitos a racionalidades distintas, não obstante se encadearem historicamente.

Em vez de "desenvolvimento" e "subdesenvolvimento" como os dois lados da mesma moeda, marcados por diferenças estruturais, na obra de 1978, o autor descortina um processo em escala global - a civilização industrial que se difunde por meio de diversas vias de acesso. Dois casos são mencionados: o Japão da Restauração Meiji e a Rússia da revolução bolchevique. Em vez de uma autêntica mutação, percebe-se aqui um comportamento reativo de coletividades que temem por sua soberania ameaçada.

No Japão, os grupos sociais tradicionais se associam com o objetivo de impulsionar a industrialização num quadro institucional "fundamentalmente distinto". Na Revolução Russa, a transformação da superestrutura mostra-se ainda mais radical, moldada para "um mundo de abundância", mas destinada a "acelerar o desenvolvimento das forças produtivas". Trata-se de um paradoxo, que teria levado à "prevalência dos meios sobre os fins", de maneira similar ao papel jogado pela acumulação sob o capitalismo (Furtado, 1978, p. 42-45). ${ }^{8}$

\footnotetext{
${ }^{7}$ Ver especialmente o terceiro capítulo.

${ }^{8}$ Nessa obra, Furtado (1978) desenvolve uma rica análise crítica sobre a experiência soviética, que não será aprofundada aqui por não ser o objetivo do presente texto.
} 
Se essas vias de acesso à civilização industrial resultaram da "consciência do atraso" em relação aos países que se industrializaram ao longo do século XIX, uma terceira via de acesso, indireta, é conformada pelos países em que a inserção na divisão internacional do trabalho se efetivou por meio de uma situação de "dependência estrutural". No caso dos países periféricos, houve "modernização" de certos padrões de consumo e uma acumulação localizada "fora do sistema produtivo". Os valores ideológicos importados reforçaram a estrutura de dominação externa, que se aproveitou das relações sociais existentes ou as adaptou aos propósitos das elites locais/nacionais associadas às provenientes dos países centrais (Furtado, 1978, p. 45-47).

Procurou-se, aqui, registrar de forma sumária e fidedigna o novo aparato metodológico construído por Furtado, de modo a "globalizar" a sua reflexão para além do eixo Estados Unidos/América Latina. A questão que interessa agora é a seguinte: qual o lugar da China nesta síntese histórica acerca do duplo processo de expansão e difusão da civilização industrial?

As considerações sobre a China, que constam do sexto capítulo da obra, impressionam por condensarem informações de cunho filosófico e histórico, as quais se lhe afiguram decisivas para a compreensão da experiência chinesa do ponto de vista econômico. Apesar da sua exemplaridade, o processo de reconstrução social em curso, "qualquer que seja a direção que tome", terá projeções planetárias. Isso porque, "pela primeira vez”, tentou-se na prática “uma opção global à civilização industrial” (Furtado, 1978, p. 106-107).

Obviamente, Furtado não era adepto da Revolução Cultural Chinesa. Mas em vez de "condenar" o processo histórico por uma atitude valorativa externa à sua dinâmica intrínseca, ele procura conhecer as suas camadas mais profundas, fazendo uso do método histórico comparativo, de modo a antever possibilidades de transformação estrutural.

Quem serve de contraponto à China é a União Soviética. O primeiro caso lhe parece diametralmente oposto ao do segundo. ${ }^{9}$ Ora, a China pretende levar a cabo a "destruição sistemática da superestrutura a partir de outra

\footnotetext{
${ }^{9}$ Não deixa de ser interessante notar que, beneficiado pelo distanciamento histórico, o historiador Perry Anderson pôde contrastar a rápida desintegração do Estado Soviético nos anos 1990 com a experiência chinesa, que adentra o século XXI combinando soberania nacional, transformação econômica e "paz social”. A China, ao contrário da URSS, conseguiu parir novas lideranças políticas e angariar "consentimento popular" sob diferentes formas desde 1949. No seu entender, “A Revolução Chinesa, embora inspirada na russa, inverteu praticamente todos os seus termos" (Anderson, 2018, p. 23-30). O livro original em inglês é de 2010.
} 
racionalidade de fins", a qual deve servir de condição para construção de uma "nova infraestrutura material" (Furtado, 1978, p. 107-108).

Quatro "linhas de força" marcam a disparidade das experiências comunistas nos dois espaços: 1) na China, a recepção de Marx se dá pela filosofia das contradições como estímulo à criatividade social, ao passo que na União Soviética predomina a "visão positivista do processo social";2) se a Revolução Cultural visa superar as estruturas tradicionais, a prática soviética está alicerçada na planificação centralizada e rígida das atividades econômicas, mantendo as hierarquias existentes; 3) enquanto o pensamento de Lênin se mostra "operativo" e "analítico", o de Mao é "sintético e se expressa por meio de um discurso poético", fundando-se nas potencialidades do todo social, portanto, sem formalismos; 4) o "evolucionismo positivista" soviético contrasta com o raciocínio profundamente dialético em busca da "coerência de direção do sistema”, marca do pensamento chinês (Furtado, 1978, p. 109-110).

O contraponto revela-se sumário e genérico. E a aposta de Furtado, arriscada. Ele escreve em 1978, em meio ao acirramento da disputa entre Estados Unidos e União Soviética, e quando a China mal ingressa no período de reformas econômicas. Não obstante, o veredito é poderoso: "nenhum outro país reúne as condições para escapar ao campo gravitacional da civilização industrial". Em seguida, completa: "todos os demais são periféricos", referindo-se aos países que compunham o então chamado Terceiro Mundo (Furtado, 1978, p. 111).

O que Furtado entende por "escapar ao campo gravitacional da civilização industrial"? A resposta vem logo adiante: a luta contra a dependência não significa recuo ou isolamento, mas o avanço pela via das relações internacionais para alterá-las qualitativamente. Trata-se de modificar a "conformação global do sistema" a partir de dentro, estabelecendo espaços internos de autonomia decisória e aumentando a capacidade de barganha sobre os países capitalistas centrais e as empresas transnacionais.

As reflexões de Furtado sobre a China aqui sintetizadas podem ser lidas sob dois ângulos: a nação asiática passa a ocupar lugar importante no radar de Furtado. E, talvez mais importante, o seu arsenal metodológico permite perscrutar a experiência chinesa sob nova perspectiva. Mas toda a cautela é necessária, pois a China aparece apenas como hipótese que exige aprofundamento.

Vale lembrar ainda que, por mais que Furtado não o explicite, o desenvolvimento chinês posterior a 1978 dá início a um conjunto de rupturas. A 
Revolução Cultural teria sido importante (não existe juízo de valor aqui) ao assegurar a homogeneidade social.

A primeira visita do economista à China ocorreu depois da escrita do livro, cujo prefácio é de julho de 1978. O nome de Furtado é então cogitado para reitor da Universidade das Nações Unidas (UNU), com sede em Tóquio (Furtado, 2019, p. 258). Mesmo não tendo assumido o cargo, a sua participação em atividades internacionais torna-se mais rotineira. Em novembro do mesmo ano, ele se deleita ao participar, em Kyoto, no Japão, de conferência com "scholars asiáticos" sobre o tema "criatividade nas culturas endógenas" (Furtado, 1991, p. 263).

A menção da viagem de Furtado à China aparece em seus diários com anotação realizada em Paris ao final de novembro de 1980 (Furtado, 2019, p. 270). No seu terceiro livro de memórias, na parte IV intitulada "do utopismo à engenharia social", ele se dedica a reflexões sobre as experiências revolucionárias de vários países, tais como União Soviética, Cuba, Mongólia e China.Todos os artigos são datados e provavelmente copiados de seus cadernos de anotações. A China aparece com dois artigos, um de novembro de 1980, escrito em Cantão, quando se refere à sua primeira visita ao país asiático. $\mathrm{E}$ outro, redigido em Paris, em abril de 1983, com o título "Revisitando a China", escrito após a sua segunda visita.

Esses dois artigos são relatos curtos sobre a China, procurando sintetizar para si mesmo o que leu, viu e ouviu durante as viagens. São parcos de detalhes sobre as visitas, mas parecem confirmar as reflexões realizadas dois anos antes em sua obra, embora se caracterizem pelo alto nível de generalidade.

O artigo de 1980 revela a "descoberta desconcertante" da China "para nós, ocidentais". Traça um rápido e arguto panorama histórico com o objetivo de ressaltar o anseio que move os governantes chineses: "manter ou restaurar a unidade territorial". Destaca a importância da estrutura burocrática "sem similar em outras partes do mundo por sua eficácia". Assim se explica o avanço persistente da sua "civilização material” (Furtado, 1991, p. 320-321).

Em seguida, caracteriza a comuna rural chinesa como um sistema de autogoverno marcado por considerável divisão social do trabalho. Boa parte da renda dos camponeses é in natura, dependendo a renda monetária do excedente retido pelo Estado. Para além da agricultura, existem outros tipos de emprego nesses espaços rurais. Furtado ressalta a importância das reformas "promovidas", dois anos antes, pelos "sucessores de Mao". Trata-se de compatibilizar no campo e nas cidades a maior liberdade de ação aos empreendimentos 
com o "indispensável centralismo" dos setores estratégicos. Esse dilema não é de pouca monta assim como "a coordenação das projeções sociais oriundas da diversificação da oferta de produtos finais" (Furtado, 1991, p. 322-323).

Enfim, o dilema reside em como conciliar acumulação de capital num quadro marcado pela homogeneidade social. A utilização de toda mão-de-obra disponível pode acarretar certa "morosidade no avanço tecnológico, mas é de inegável alcance social". Os avanços tecnológicos concentram-se nos setores considerados estratégicos pelo Estado. Mas essa heterogeneidade tecnológica pode atenuar as tensões sociais, na medida em que "o econômico e o social operem como esferas autônomas" (Furtado, 1991, p. 324).

Já no artigo de 1983, Furtado afirma que "qualquer raciocínio de base analógica será de escassa valia" no caso do gigante asiático. Conforme sua observação, os chineses não se imaginam uma nação subdesenvolvida ou dependente, e sim atrasada". O que lhes falta é "modernizar-se" para ocupar a posição que lhes corresponde no mundo. Aqui o "sistema de cultura" "extrai das próprias raízes o que é fundamental". Nosso intelectual então retoma a análise empreendida no livro de 1978: se a opção é fazer parte da "civilização planetária" como lidar com o "enorme atraso tecnológico"? (Furtado, 1991, p. 325).

É interessante como Furtado recorre à estratégia geopolítica chinesa no novo quadro mundial: "buscam por todos os meios um lugar na família do Terceiro Mundo". O objetivo não é se opor ao Norte, mas ampliar as múltiplas formas de cooperação, completa o economista.Tal mudança na sua estratégia internacional reside no fato de que a China jamais teria adotado uma "ideologia totalitária". A ideologia cumpre um papel de preparar as mudanças em face de novos contextos, "emprestando legitimidade ao sistema como um todo". Nesse sentido, "o socialismo chinês está longe de se haver fossilizado" (Furtado, 1991, p. 325-326).

Longe de pintar o intelectual como "visionário", ou como alguém que "previu" o "sucesso" chinês, procuramos mostrar como o esquema metodológico de Criatividade e dependência permite uma compreensão multifacetada da China em transformação num contexto em que a dinâmica do capitalismo apresenta novas fraturas entre os vários centros e periferias. Contudo, a ascensão chinesa pós-1980 - que Furtado trabalha como hipótese - não está isenta de contradições e nem de irrupções sociais. 


\section{Ascensão chinesa e complexificação do sistema centro-periferia}

Nos anos 1990, Furtado escreve dois pequenos livros em que procura traçar as novas coordenadas da economia capitalista mundial. No seu entender, o período 1945-1973 "não conduziu propriamente à formação de um sistema econômico global", mas "a um conjunto de grandes subsistemas cujas relações mútuas estão longe de ser simétricas". O período posterior marca não uma crise, mas uma "complexa transição estrutural com reacomodações nas relações entre os centros de poder, tanto de natureza econômica como política". O novo sistema de poder internacional pende para a "multipolaridade", pois a consolidação das estruturas de poder transnacionais acarreta "o debilitamento dos atuais centros nacionais" (Furtado, 1992, p. 14-17).

Nesse contexto, a economia estadunidense perde coerência sistêmica em virtude da sua abertura externa. A "globalização" não significa a expansão linear de uma economia global hipotética, mas a "desarticulação dos sistemas econômicos nacionais" inclusive nos países centrais. $\mathrm{O}$ mesmo acontece com a Europa em sua experiência plurinacional em virtude de sua dependência do mercado financeiro internacional (Furtado, 1992, p. 18-19, 24-26, 34).

Depois de traçar os contornos da nova ordem mundial, o economista recupera as teorias e experiências de superação do subdesenvolvimento. É então que a China volta a ocupar um papel de destaque. No entender de Furtado (1992, p. 48), trata-se do "exemplo mais conspícuo" de tentativa de superação das "taras do subdesenvolvimento" numa região de baixa produtividade e no contexto de "revolução social". Depois de assegurada a "homogeneidade social", a acumulação foi canalizada para o desenvolvimento das forças produtivas sob o planejamento centralizado.

A leitura da reflexão sucinta de Furtado permite enumerar alguns dilemas: como assegurar um sistema de decisões de extrema complexidade fundado na rigidez, tendo em vista a necessidade de influenciar o comportamento de milhões de unidades produtivas? Como assegurar o retorno às relações de mercado sem trazer de volta a concentração de renda? Como manter o isolamento sem impactar negativamente a eficácia econômica?

Ao final de seu raciocínio, nosso economista conclui: “a China jamais reproduzirá os padrões de consumo das nações industrializadas, qualquer que seja a política que se adote", por serem "demasiado custosos em termos de utilização de recursos não-renováveis", caso universalizados à população chinesa. Cabe à nação continental optar "entre a homogeneidade social a 
modestos níveis de consumo" e o "acentuado dualismo social com maiores ou menores disparidades regionais e sociais" (Furtado, 1992, p. 49). Hoje parece evidente a adoção da segunda alternativa apesar da relativa consciência das lideranças chinesas sobre a necessidade de redução das disparidades crescentes.

Furtado aponta, em seguida, os casos de Coreia do Sul e Taiwan, que lograram alcançar um grau elevado de homogeneidade social por meio de reformas (agrária e educacional), sem descuidar da busca por autonomia tecnológica, tendo assim "superado a barreira do subdesenvolvimento". Portanto, a homogeneização social por si só se mostra insuficiente se não vier acompanhada de relativa autonomia tecnológica, que por sua vez requer: descentralização das decisões via mercado, ação orientadora do Estado baseada numa estratégia de desenvolvimento e exposição à concorrência internacional (Furtado, 1992, p. 49-52).

Essa afirmação representa, ao contrário do que imaginam os seus não leitores e detratores, uma das balizas do pensamento furtadiano. O economista brasileiro jamais defendeu um modelo de crescimento fechado e autossuficiente. Ao detectar, nos anos 1950 e 1960, que a industrialização no Brasil e na América Latina se dava por "substituição de importações”, não deixou de ressaltar que o núcleo do mercado interno deveria levar à diversificação exportadora inclusive nos setores de vanguarda. Isso exigiria o acesso de tecnologia moderna por empresas nacionais (públicas ou privadas) por meio de contratos de cessão com as transnacionais.

Em outro capítulo de Brasil: a construção interrompida, o mestre propõe-se a recuperar a visão global de Prebisch. O economista argentino não concebia "a economia internacional como um sistema que apenas se reproduz", mas movido "pelo impulso da propagação do progresso técnico". Para entender o quadro global, faz-se necessário penetrar no dinamismo autônomo das economias centrais e mostrar como elas articulam-se entre si, impactando o tipo de inserção externa e as possibilidades de desenvolvimento das economias periféricas (Furtado, 1992, p. 63).

No seu entender, essa primeira vertente deveria ser aprofundada por uma segunda vertente analítica, capaz de averiguar as modificações nas relações entre as economias centrais, e em especial, como isso afeta a posição estadunidense como "centro principal”. Furtado (1992, p. 71-72) conclui então sobre a necessidade de novas formas de regulação globais, na medida em que "a possibilidade de que uma só economia exerça o papel de centro principal 
já não existe". Mais adiante, ele arremata: "é de admitir que surja uma hierarquia de poder, de corte mais policêntrico" (Furtado, 1992, p. 84).

A reflexão de Furtado não chega a conectar as mudanças do padrão de desenvolvimento chinês com as novas coordenadas da economia mundial capitalista, até porque a China apenas iniciava seu processo de ascensão econômica e geopolítica. Mas ele nos lança pistas para armar esse quebra-cabeça, por meio da aposta no policentrismo, o que se deve ao acompanhamento das tendências econômicas dos Estados Unidos e da União Europeia - esta última ainda em processo de construção.

Já no livro O capitalismo global, o economista integra as duas dimensões do cenário em transformação. Furtado ressalta uma vez mais a "desarticulação da ação sincrônica das forças que garantiram no passado o dinamismo dos sistemas econômicos nacionais" nos países centrais (Furtado, 1998, p. 29). Ele tem em mente as forças econômicas que dialeticamente se entrosaram com forças sociais e políticas para conformar o que Arrighi (1996, p. 283-309) chamou de "ciclo sistêmico de acumulação sob hegemonia estadunidense", ancorado no seguinte tripé: capitalismo de corporações (das empresas transnacionais), o sistema de Bretton Woods e a supremacia militar dos Estados Unidos.

Ao final dos anos 1990, o quadro global aparece marcado pelos seguintes elementos estruturantes: 1) declínio da governabilidade das economias centrais, em virtude da internacionalização dos mercados financeiros;2) a construção da União Europeia; 3) o traumático processo de conversão dos países do Leste Europeu à economia de mercado, levando à "marginalização da Rússia"; 4) a emergência das nações asiático-orientais - em particular da China - que passam a redefinir a ordem do planeta; 5) o agravamento das heterogeneidades sociais da América Latina em face da desregulamentação dos mercados. Vale lembrar que a ascensão asiática, ainda aparece sob a liderança japonesa, residindo o êxito da região na autonomia no domínio das técnicas que se beneficiam da disciplina social (Furtado, 1998, p. 30-32).

É preciso insistir: não se trata de tecer loas ao intelectual por seus "acertos" ou de condená-lo pelos seus "erros". Mas de mostrar como a ampliação do seu arsenal metodológico permitiu que a China entrasse no seu radar, primeiro, como laboratório de análise econômica e social em virtude do seu potencial para "escapar ao campo gravitacional da civilização industrial", integrando-se a ele de maneira soberana; e, segundo, por sugerir de maneira implícita que, ao fazê-lo, acarreta "mudanças tectônicas" no funcionamento 
do "capitalismo global" e dos centros de poder geopolíticos. Isso porque a China se aproveita da "desarticulação dos sistemas econômicos nacionais" de Estados Unidos e União Europeia, seja em virtude da integração dos mercados financeiros, seja em virtude da atuação das empresas transnacionais desses países para além dos interesses nacionais e dos seus respectivos mercados internos.

Partindo das suas categorias, não seria o caso de dizer que a China pós1980 logra fundir os dois padrões históricos decodificados por Furtado (2000, p. 117) - o "capitalismo dos sistemas nacionais" (1850 a 1950) e o "capitalismo das grandes firmas transnacionais" (1950 a 1980)? Isso porque, na China dos últimos quarenta anos, o primeiro padrão parece integrar o segundo para adaptá-lo aos interesses do desenvolvimento nacional com transformações estruturais que se projetam no plano internacional. ${ }^{10}$

Dessa forma, estabelecem-se relações de maior horizontalidade - envolvendo complementaridade e conflito - entre a China e os antigos centros (Estados Unidos e União Europeia), que não saem de cena. A ruptura é de tal ordem, que exige a confecção de novas ferramentas conceituais e teóricas para a compreensão da dinâmica totalmente reconfigurada da economia-mundo capitalista, ancorada agora numa estrutura de poder multicêntrica e com impactos profundos sobre as diversas semiperiferias e periferias.

\section{Breve depoimento à guisa de conclusão}

Entre 2002 e 2019, tive a oportunidade de visitar seis vezes a China. Não posso dizer que conheci a China, pois eram viagens de curta duração a algumas das metrópoles e cidades localizadas no leste do país.

O impacto também foi "desconcertante". Além do mergulho numa experiência cultural diferente da ocidental, a transformação econômica e social era algo que saltava aos olhos, tanto pela dimensão colossal das metrópoles que exprimiam o vulto e a rapidez do processo de acumulação de capital nesse território, mas também pelo comportamento dos chineses que me recepcionavam nas conferências. Transpiravam autoestima como integrantes

\footnotetext{
${ }^{10}$ Essas duas configurações históricas do capitalismo não se transportam no tempo e no espaço. O argumento aqui é mais de caráter reflexivo e exploratório do que analítico. Obviamente, ele requer maior aprofundamento teórico e empírico. Vale também ressaltar que no período pós-1980 existe uma sucessão de padrões de desenvolvimento na China (Lo, 2006; Medeiros, 2013), os quais vêm acompanhados de diferentes padrões de inserção externa desse país, além de alterarem a dinâmica da economia-mundo capitalista e as possibilidades de desenvolvimento de todas as regiões do novo sistema-mundo (Barbosa, 2019).
} 
de uma civilização que estava logrando recuperar o seu lugar ao sol no sistema mundial.

Procurei então penetrar nesse novo universo. O intuito era encontrar a chave de acesso para desvendar o segredo dessa rápida transformação, que trazia no seu encalço contradições mais ou menos visíveis. Meu objetivo era menos entender a China em si, e mais como ela impactava a economia-mundo capitalista e, por consequência, o Brasil e a América Latina.Tudo que escrevi a respeito tem como foco esta segunda temática.

O primeiro estalo partiu de um pequeno artigo de Antônio Barros de Castro, o intelectual pós-furtadiano que melhor compreendeu, dentre nós, o significado da ascensão chinesa como ruptura histórica na conformação do capitalismo. Em O espelho da China, Castro (2009) destaca a mudança do "centro de gravidade do crescimento mundial", algo que já acontecera em outros momentos da história do capitalismo, tendo imprimido a sua marca na emergência da Cepal, quando os Estados Unidos se afirmaram como o novo centro dinâmico.

Segundo Castro, a ascensão chinesa contemporânea acarreta deslocamentos no potencial de desenvolvimento em todos os pontos do planeta, o que depende da estrutura produtiva existente e do padrão de inserção externa herdado. E mais, "as oportunidades e ameaças serão frequentemente redefinidas, havendo neste sentido que atirar sobre alvos móveis", pois as transformações chinesas redefinem constantemente o tabuleiro de opções disponíveis em todos os territórios da economia-mundo capitalista. Finalmente, o autor defende a revisão das estratégias de desenvolvimento, pois parte do pressuposto de que não existe mais possibilidade de "industrialização integral", mesmo nas economias centrais dotadas de estruturas produtivas complexas e maduras (Castro, 2008, 2009).

Esse resgate de uma perspectiva cepalina e furtadiana renovadas, a partir de Castro, ajudou-me a colocar a questão sob outro prisma, para além das abordagens esposadas pela economia convencional ou pelo marxismo ortodoxo.

Nos meus artigos, propus-me a realizar um diálogo entre os conceitos de Fernand Braudel, Giovanni Arrighi, Immanuel Wallerstein e os elaborados por Raúl Prebisch e Celso Furtado, para entender a nova conformação da economia-mundo capitalista no contexto da ascensão chinesa. No meu entender, trata-se de um "novo centro de gravidade", que gera deslocamentos nos outros dois centros - Estados Unidos e União Europeia -, além de rebatimentos 
sobre a semiperiferia e a periferia. Na prática, essas posições estruturais aparecem completamente redefinidas.

A conexão entre Celso Furtado e os autores que partem dos conceitos de economia-mundo e de sistema-mundo é endossada pelo economista brasileiro em seminário realizado na Itália em abril de 1978. Perguntado por Braudel, durante o evento, se ele partilha do universo conceitual dele e de Wallerstein, Furtado responde que, desde a Cepal, o esforço para identificar os problemas específicos dos países subdesenvolvidos sempre partira de um "quadro global": "era, digamos, o início do conceito de economia-mundo, isto é, do conceito centro-periferia" (D'Aguiar, 2020, p. 220-221). Portanto, os conceitos parecem intercambiáveis entre si, apesar de operacionalizados de diferentes formas, de acordo com os interesses de cada intelectual e das escalas geográficas priorizadas.

Entretanto, há diferenças entre os autores. Braudel (1985) encara a topografia da vida econômica como composta de camadas: o capitalismo (o "contra-mercado"), a economia de mercado e a zona do autoconsumo. O capitalismo tende a se localizar prioritariamente nos lugares centrais da economia-mundo, o que não impede que estabeleça relações com as outras camadas da vida econômica nessas áreas, ou mesmo que o capitalismo possa emergir como que enquistado fora da economia-mundo europeia antes da Revolução Industrial. Wallerstein (1983, p. 15-19), por sua vez, transforma o capitalismo num conceito mais genérico e amplo - "produção para o mercado distante voltada para o lucro" -, de modo a priorizar as posições estruturais (centro, semiperiferia e periferia) e as suas respectivas e diferenciadas relações de produção advindas do padrão de inserção externa na economia-mundo capitalista, hegemônica desde o século XIX. Já Arrighi (1996) acompanha as transformações da economia-mundo capitalista a partir dos ciclos sistêmicos de acumulação e de seus respectivos centros hegemônicos, ressaltando as diferentes estruturas organizacionais do capitalismo. Estas se projetam sobre o conjunto da economia-mundo capitalista, conformes as suas diversas configurações históricas, encontrando-se alicerçadas na competição que tem lugar no sistema interestatal.

Em 1994, Arrighi (1996, p. 19) se pergunta se "as alianças entre os poderes do Estado e do capital" nos países centrais não teriam se tornado tão "impressionantes" de modo a "impedir a emergência de novas potências capitalistas de ordem superior", ou seja, capazes de atuar como novos centros hegemônicos. Porém, em obra posterior, Arrighi (2007) utiliza a China como 
território que se destaca pela emergência de um padrão de desenvolvimento market-based, que não caminha necessariamente para o padrão de desenvolvimento capitalista propriamente dito. A sua ascensão se explica pela crise do centro hegemônico estadunidense. Arrighi parece então comungar da aposta de Furtado em 1978, por mais que o seu repertório conceitual seja outro.

Qual a contribuição de Furtado para esse debate? Em Criatividade e dependência na civilização industrial, ele situa a vasta região periférica a partir das suas relações de dependência com os países centrais, inclusive destacando as diferentes formas de apropriação do excedente. É então que Furtado realiza, como vimos, a sua aposta de que a China seria o único país em condições de "escapar ao campo gravitacional da civilização industrial”, pois “todos os demais são periféricos” (1978, p. 111); já no livro de 1992 (p. 49), mesmo num contexto de crescente busca por autonomia tecnológica, Furtado admite, conforme apontamos, que o país asiático terá que optar "entre a homogeneidade social a modestos níveis de consumo" e o "acentuado dualismo social com maiores ou menores disparidades regionais e sociais".

Seu foco se concentra mais nas renovadas contradições internas do que no efeito impulsionador de mudanças no funcionamento do capitalismo e das relações entre centros, semiperiferias e periferias, até porque isso teria ficado mais patente apenas na primeira década dos anos 2000.

Nesse sentido, apesar das peculiaridades da formação social chinesa e do papel do Estado na gestão do processo de desenvolvimento, a existência de locais privilegiados de acumulação de capital sob novas bases organizacionais funciona como ponta de lança de penetração da China na economia-mundo capitalista, completamente reorganizada.

A articulação dessas duas tradições sistêmicas de reflexão sobre o capitalismo norteou a minha reflexão sobre a América Latina no período recente. O objetivo era mostrar como a ascensão chinesa, associada à reconfiguração da economia-mundo capitalista, engendra uma complexificação do sistema centro-periferia com contornos e significados bem diversos do quadro descrito e analisado por Prebisch e Furtado para a segunda metade do século XX.

Por meio dessa reflexão, procurei enfrentar duas controvérsias. A primeira, ao questionar a interpretação corrente nos anos 2000 de que o boom de commodities havia "enterrado" a Cepal. Ora, a deterioração dos termos de troca era a forma pela qual se dava a concentração do progresso técnico, conforme Prebisch. Uma melhoria dos termos de troca para a América Latina como a propiciada pela ascensão chinesa não impede a emergência de 
novos mecanismos de concentração do progresso técnico em escala global, o que depende das formas de apropriação do excedente conforme os termos de Furtado (Barbosa, 2011).

Portanto, a contribuição do pensamento econômico cepalino não reside apenas na constatação empírica da deterioração dos termos de troca, mas na investigação do quadro mais amplo das relações entre centro e periferia num contexto em que os Estados Unidos atuavam como centro hegemônico. Nesse sentido, ela pode e deve ser atualizada no contexto da ascensão chinesa, especialmente se enriquecida pelo debate com os demais autores aqui citados.

A segunda controvérsia está relacionada à maneira como se assimilou a ideia da "desindustrialização" no Brasil num contexto de ascensão chinesa com valorização cambial. Se o risco de esvaziamento da estrutura produtiva e industrial se transformou numa realidade concreta, pouco se avançou numa análise histórico-estrutural sobre a dinâmica da "desindustrialização". A ausência de uma reflexão teórica e empírica segundo essa perspectiva metodológica pode levar a uma concepção ingênua de que basta uma "reindustrialização". Não seria mais apropriado indagar qual o sentido de um projeto de recuperação da estrutura produtiva e do parque industrial no território nacional, com o apoio de quais segmentos de classe e com foco em quais setores e cadeias, no contexto desta nova economia-mundo capitalista que tem a China como um dos seus principais centros de poder econômico e político? Com certeza, não será uma estratégia voltada a dar continuidade ao processo "interrompido" em 1980.

Este breve depoimento sobre a minha "aventura chinesa" tem o objetivo de lançar algumas questões e de revelar como o presente artigo me permitiu encarar a China diretamente pelas lentes de Furtado. Até então, eu imaginava estar instrumentalizando o método furtadiano, com todas as minhas limitações, para compreender a ascensão chinesa. Se a hipótese lançada aqui estiver correta, é possível se escorar em Furtado nas suas reflexões sobre o desenvolvimento chinês (depois de 1978) e sobre os seus impactos no sistema mundial, ainda que ele tenha se detido menos nesse último aspecto, desenvolvido por Antônio Barros de Castro.

Isso significa dizer que a nova economia-mundo capitalista pode ser compreendida a partir das relações de complementaridade e conflitos estabelecidas entre os três grandes centros hegemônicos, e das possibilidades abertas para os países da semiperiferia e da periferia, inclusive em temos de redefinição da hegemonia de poder nos espaços multilaterais. 
Neste sentido, a afirmação, por exemplo, de que as relações comerciais entre China e Brasil seguem o modelo centro-periferia, se não deixa de estar correta, afigura-se simplista. Ela captura apenas parte do problema, que reside na compreensão da totalidade de relações estabelecidas no bojo da economia-mundo capitalista, em constante reconfiguração, e que extravasa as relações entre os dois países.

Termino o artigo com um agradecimento. A percepção de que a China passou a ocupar papel importante na reflexão furtadiana, especialmente por conta da ampliação do seu arsenal metodológico ao final dos anos 1970, não teria sido possível sem o curso de pós-graduação ministrado no IEB no segundo semestre de 2020, intitulado Celso Furtado intérprete do Brasil: trajetória, método e obra. Junto com o professor Alexandre Macchione Saes, durante as aulas do curso, e contando com participação de todos os alunos e integrantes, pudemos descobrir novas facetas e aspectos da obra inesgotável do mestre.

\section{Referências}

ANDERSON, P. Duas revoluções: Rússia e China. São Paulo: Boitempo Editorial, 2018.

ARRIGHI, G. Adam Smith in Beijing: lineages of the twenty-first century. Londres: Verso, 2007.

ARRIGHI, G. O longo século XX. Rio de Janeiro:Editora Contraponto, 1996.

BARBOSA, A. de F. China e América Latina na nova divisão internacional do trabalho. In: LEÃO, Rodrigo Pimentel Ferreira; COSTA PINTO, Eduardo, ACIOLY, Luciana (Org.). A China na nova configuração global: impactos políticos e econômicos. Brasília: IPEA, p. 269-305, 2011.

BARBOSA, A. de F. El ascenso chino, las transformaciones de la economia-mundo capitalista y los impactos sobre los patrones comerciales em América Latina. In: SALAZAR, Cecilia; SEOANE, Alfredo. La región Asia-Pacifico: desafios para el desarrollo, hoy. La Paz: CIDEZ-UMSA, p. 207-241, 2019.

BRAUDEL, F. La dynamique du capitalisme. Paris: Les Éditions Arthaud, 1985. 
CASTRO, A. B. de. O espelho da China. Rio de Janeiro: Instituto de Pesquisa Econômica Aplicada, 2009.

CASTRO,A. B. de. From semi-estagnation to growth in a sino-centric market. Brazilian Journal of Political Economy. v. 28, n. 1, p. 3-27, 2008.

D’AGUIAR, R. F. Anos de formação (1938-1948). Arquivos Celso Furtado 6. Rio de Janeiro: Editora Contraponto/Centro Celso Furtado, 2014.

D'AGUIAR, R. F. Um encontro entre Celso Furtado e Fernand Braudel. Revista de Estudos Avançados. v. 34, n. 100, p. 279-290, 2020.

FURTADO, C. M. (1961). Desenvolvimento e subdesenvolvimento. Rio de Janeiro: Fundo de Cultura, 1965.

FURTADO, C. M. (1969). A economia latino-americana. São Paulo: Companhia Editora Nacional, 1986.

FURTADO, C. M. (1976). Prefácio à nova economia política. Rio de Janeiro: Paz e Terra, 1977.

FURTADO, C. M. Criatividade e dependência na civilização industrial. Rio de Janeiro: Paz e Terra, 1978.

FURTADO, C. M. (1980). Introdução ao desenvolvimento: enfoque histórico-estrutural. São Paulo: Paz e Terra, 2000.

FURTADO, C. M. Os ares do mundo. Rio de Janeiro: Paz e Terra, 1991.

FURTADO, C. M. Brasil: a construção interrompida. Rio de Janeiro: Paz e Terra, 1992.

FURTADO, C. M. O capitalismo global. São Paulo: Paz e Terra, 1998.

FURTADO, C. M. Diários intermitentes: 1937-2002. Organização, apresentação e notas de Rosa Freire d'Aguiar. São Paulo: Companhia da Letras, 2019. 
LO, D. Making sense of China's economic transformation. Londres: School of Oriental and African Studies, University of London, 2006.

MALLORQUIN, C. Celso Furtado: um retrato intelectual. São Paulo: Editora Xamã; Rio de Janeiro: Editora Contraponto, 2005.

MEDEIROS, C. A. Padrões de investimento, mudança institucional e transformação estrutural na economia chinesa. In: Padrões de desenvolvimento econômico (1950-2008): América Latina, Ásia e Rússia. Volume 2. Brasília: CGEE, p. 435-489, 2013.

WALLERSTEIN, I.The rise and future demise of the world capitalist system: concepts for comparative analysis. In: The capitalist world-economy. Cambridge: Cambridge University Press, 1983. 